\title{
Quantifying shortening of the fractured clavicle assuming clavicular symmetry is unreliable
}

\author{
Paul Hoogervorst ${ }^{1} \cdot$ Anand Appalsamy $^{1} \cdot$ Sebastiaan Franken $^{2} \cdot$ Albert van Kampen $^{1} \cdot$ Gerjon Hannink $^{1}$
}

Received: 6 November 2017 / Published online: 13 March 2018

(c) The Author(s) 2018

\begin{abstract}
Background One of the more commonly used methods of determining the amount of shortening of the fractured clavicle is by comparing the length of the fractured side to the length of contralateral unfractured clavicle. A pre-existing natural asymmetry can make quantification of shortening using this method unreliable. The goal of this study is to assess the sideto-side variation in clavicle length in 100 uninjured, skeletally mature adults.

Materials and methods To assess the side-to-side difference in clavicle length the length of both clavicles of 100 patients on thoracic computed tomography (CT) scans were measured. Patients without a history of pre-CT clavicular injury were included. The measurements were allocated into three groups based on the amount of asymmetry $(<5, \geq 5-10$ and $>10 \mathrm{~mm})$. Dominant side and sex were analyzed to determine influence on the length of the clavicle.

Results In 30 patients (30\%), an asymmetry of $5 \mathrm{~mm}$ or more was found. $2 \%$ of the patients had a side-to-side difference of more than $10 \mathrm{~mm}$. The absolute side-to-side length difference (LD) was $3.74 \mathrm{~mm}(95 \%$ CI 3.15-4.32; $p<0.001)$. A significant association between clavicle length and dominant side or sex was found $(p<0.001)$.

Conclusion These results show that by utilizing a treatment algorithm based upon clavicular symmetry has a potential for error and can lead over- or under-treatment of the fractured clavicle. A significant association between clavicle length and dominant side or sex was found $(p<0.001)$.
\end{abstract}

Level of evidence 2 .

Keywords Clavicle $\cdot$ Length $\cdot$ Symmetry $\cdot$ Interobserver agreement $\cdot$ Imaging

\section{Introduction}

Clavicle fractures are common fractures with a prevalence of 59.3 per 100,000 person-years [1]. The majority of these fractures are shortened and/or displaced due to the specific anatomy and muscle insertions. There is still no consensus on how to treat these displaced and/or shortened midshaft clavicle fractures (DMCF). Operative treatment leads to better rates of union, less mal-unions, and increased patient satisfaction in comparison to conservative therapy, but it

IRB: CMO Arnhem-Nijmegen (2014-1432).

Paul Hoogervorst

paul.hoogervorst@hotmail.com

1 Department of Orthopedics, Radboud University Medical Center, P.O. Box 9101, 6500 HB Nijmegen, The Netherlands

2 Department of Radiology, Radboud University Medical Center, Nijmegen, The Netherlands is accompanied by a higher rate of adverse events [2,3]. A recent meta-analysis by Kong et al. [4] of six randomizedcontrolled trails (RCTs) comparing conservative and operative treatments supports these findings. Other studies report on increased pain, loss of strength, rapid fatigue, hyperesthesia of the hand and arm, difficulty sleeping on the affected side, and aesthetic complications in conservatively treated, malunited, and shortened clavicles [5-7]. These may be the reasons why in recent years there is a tendency to surgically reduce and fixate DMCF [5-10]. Current treatment paradigms support the indication for surgery if the fractured clavicle is shortened more than $15-20 \mathrm{~mm}$, or displaced more than the diameter of the clavicle's shaft $[2,5,7,9$, 11-13].

Since the clavicle has a sigmoid shape in two planes, adequately quantifying shortening of the fracture elements is challenging. Other variables influencing measurements on the fractured clavicle are patient positioning, magnification, and direction of the X-rays [14-16]. Various methods 
to quantify shortening, such as clinical measurements and the use of CT scans, have been described [16-18].

A commonly used technique is using $\mathrm{AP}$ and $15^{\circ}$ caudocranial views. However, there are papers which support the use of a $15-30^{\circ}$ cranio-caudal AP or PA views. In addition, a PA thorax view is used in measuring the shortening of DMCF [14, 16-18]; Silva et al. [17] proposed a standardized method of measuring shortening in DMCF, even though no better interobserver agreement was shown.

It remains unclear which method or technique would be best to quantify shortening of the fractured clavicle.

Another commonly used method is to determine the amount of shortening by comparing the fractured side to the contralateral unfractured clavicle on a panoramic AP view of both clavicles. This presumes clavicular symmetry. To our knowledge, there is only one study that investigated clavicular symmetry. Cunningham et al. [19] reported an asymmetry of clavicular length of $5 \mathrm{~mm}$ or more in $28.5 \%$ of the studied population and found no association between side-to-side differences and sex. However, they did not exclude pre-CT clavicular injuries or investigate associations between side-to-side differences and hand dominance. This might be valuable, since hand dominance is associated with differences in upper limb bone mineralization and hand size [20, 21].

Because, in recent years, an absolute shortening of $15 \mathrm{~mm}$ is thought to be a relative indication for surgery, [5, 9, 13], a pre-existing asymmetry of $5 \mathrm{~mm}$ or more in an important part of the population may lead to the conclusion that quantifying shortening using this method is unreliable [19].

The goal of this study was to assess the side-to-side difference in clavicle length in 100 skeletally mature adults without any pre-CT clavicular injuries, and to investigate possible associations between clavicular length and sex or hand dominance.

\section{Methods}

\section{Design}

To assess the side-to-side differences in clavicle length, we measured the length of both clavicles of 100 patients on 100 thoracic computed tomography (CT) scans. The study protocol was approved by our institutional review board (CMO 2014-1432).

\section{Patients}

Each thoracic CT scan that was made between September 2014 and February 2015 in our institution for any reason was first assessed if both clavicles were completely and adequately imaged. If so, we contacted each patient of whom we would like to use the CT scan. During the phone interview, verbal consent was given by patient involved to use their images. All patients were over 18 years old. Only those patients without a history of pre-CT clavicular injury were included. All patients included stated their dominant side.

A total of 132 scans were evaluated. Two patients did not want their thoracic CT scan to be included. Twelve patients could not be reached on multiple occasions. Three patients were deceased. Fifteen were excluded due to a clavicular fracture in the past.

\section{Measurements}

Two observers [SF (radiologist) and AA (medical student)] measured both clavicles in random order on a 3D reconstruction of the CT scan using TeraRecon Aquarius Intuiton (Foster City, CA, USA). Measurements on a patient's right and left clavicle were performed on separate occasions at least 2 weeks apart to prevent bias. Before the start of the study, a training session with both observers took place and the measurement methodology was standardized. The observers agreed upon the precise definitions of the reference points. The reconstructions were projected in such a way that the length of the clavicle was maximized according to the observer. Clavicle length was defined as the distance between the lateral-most point of the clavicle in the acromioclavicular joint and the medial-most point of the clavicle in the sternoclavicular joint. The clavicle length was measured between these points using the same software (Fig. 1). The absolute side-to-side length difference (LD) between the right and left clavicles was calculated by subtracting the length of the short side (SS) from the length of the long side (LS). The LD were categorized into three groups based on the amount of asymmetry. One group included all patients in which the side-to-side difference was $<5 \mathrm{~mm}$. The other two groups consisted of those patients with an asymmetry of $\geq 5-10 \mathrm{~mm}$ and $>10 \mathrm{~mm}$ side-to-side difference. These criteria were chosen, since a $5 \mathrm{~mm}$ side-to-side difference might be clinically relevant when deciding on a surgical intervention of the fractured clavicle.

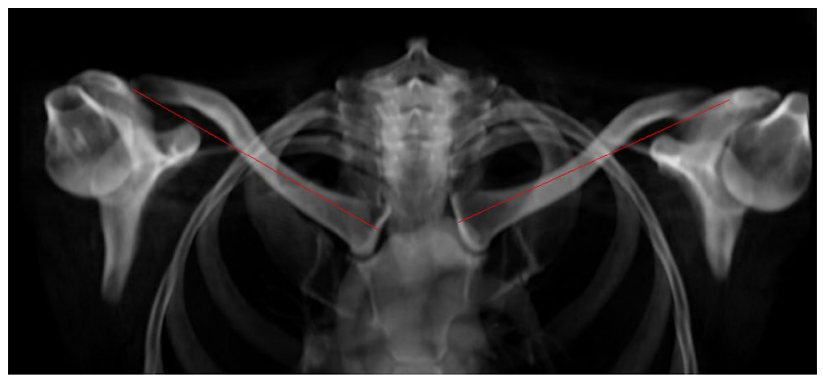

Fig. 1 Example of measurements on 3D reconstruction of a CT scan showing both clavicles 


\section{Statistical analysis}

Interobserver agreement was assessed by calculation of concordance correlation coefficients (CCC). The CCC for repeated measurements (left and right clavicle) were estimated using the variance components from a linear mixed model estimated by restricted maximum likelihood [22, 23]. Limits of agreement (LoA) were calculated to assess systematic and random measurements error between both observers.

Measurements were only performed once, since intraobserver agreement for measurements performed on CT scans is known to be high [19, 24]. Measurements of both observers were averaged when interobserver agreement was almost perfect (i.e., CCC $\geq 0.99$ ) [25].

Descriptive statistics were used to summarize the data. Paired sample $t$ tests were used to test side-to-side length differences. The associations between clavicle length and dominant side and sex were tested using linear mixed models using dominant side and sex as fixed factors and patient as random factor. $p$ values $<0.05$ were considered statistically significant. Statistical analyses were performed using R 3.3.2 (R Foundation, Vienna, Austria) with package 'cccrm' [26].

\section{Results}

The mean systematic difference in measured clavicle length between both observers was $0.88 \mathrm{~mm}$ ( $\mathrm{LoA}-2.47$ to 4.48 ). The observers showed an almost perfect agreement [CCC 0.99 (95\% CI 0.98-0.99)] and the measuremens of both observers were averaged.

Of the 100 included CT scans, 42 belonged to male and 58 to female patients. The mean age of the patients was 55.5 years (range $18-80$ years). 91 patients were righthanded and 9 were left-handed. The clavicle length measurements are presented in Table 1.

Right clavicles were $1.79 \mathrm{~mm}$ (95\% CI 0.91-2.66; $p<0.001)$ shorter than the left. The absolute side-to-side

Table 1 Clavicle length measurements

\begin{tabular}{ll}
\hline Clavicle length $(\mathrm{mm})$ & Mean (range) \\
\hline Side & \\
Left & $147.8(122.5-175)$ \\
Right & $146.0(121.5-171.5)$ \\
Gender & \\
Male & $154.8(130-175)$ \\
Female & $141.2(121.5-161)$ \\
Dominance & \\
Dominant & $146.0(121.5-171.5)$ \\
Non-dominant & $147.9(122.5-175)$ \\
\hline
\end{tabular}

length difference (LD) was $3.74 \mathrm{~mm}$ (95\% CI 3.15-4.32; $p<0.001) .28$ patients (28\%) had an asymmetry between the right and left clavicle of between 5 and $10 \mathrm{~mm}$, and $2 \%$ had an asymmetry of more than $10 \mathrm{~mm}$ (Fig. 2). Both sex [regression coefficient for males: $13.26 \mathrm{~mm}(95 \% \mathrm{CI}$ 9.85-16.67; $p<0.001)$ ] and dominant side [regression coefficient for non-dominant side: $1.77 \mathrm{~mm}$ (95\% CI 0.90-2.63); $p<0.001]$ were associated with clavicle length.

\section{Discussion}

The goal of this study was to assess the side-to-side variation in clavicle length in 100 uninjured, skeletally mature adults using CT scans. To exclude the possibility of variation due to prior clavicular fractures, only patients of whom it was ascertained no prior clavicular fractures had occurred were included. The most important finding in this study is that $30 \%$ of the studied population had an asymmetry between the right and left clavicle of $5 \mathrm{~mm}$ or more. $2 \%$ had an asymmetry of more than $10 \mathrm{~mm}$. This difference could be clinically significant when adhering to the treatment paradigm of surgically treating DMCF when shortened more than $15 \mathrm{~mm}$. There is a large potential for error that could lead over- or under-treatment of the fractured clavicle. It is debatable whether shortening should be used as an indicator for surgery, but, since there is no standardized method of measuring and imaging the fractured clavicle, it also cannot be discarded. A uniform method that takes into account natural asymmetry, patient positioning,

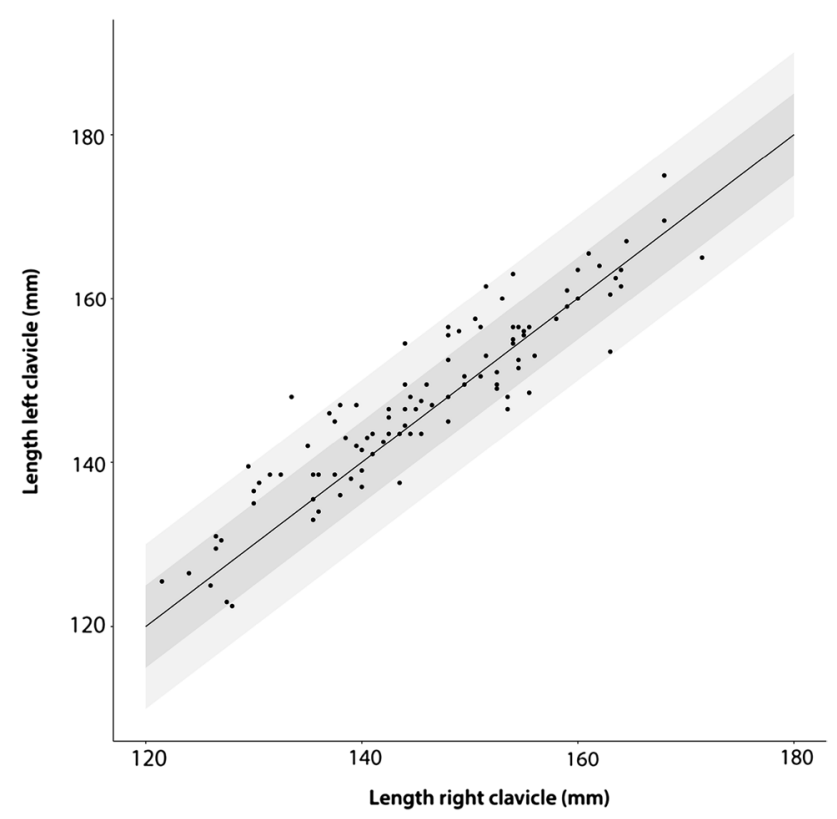

Fig. 2 Scatterplot of right versus left clavicle lengths. Dots in the dark grey area represent length differences $<5 \mathrm{~mm}$. Length differences between 5 and $10 \mathrm{~mm}$ are within the light grey area 
imaging technique, and measuring technique could potentially answer this question in the future.

CT scans were used, since this technique provides the most accurate measurements in comparison to others, such as conventional X-rays or clinical measurements [18]. Cunningham et al. [19] were the first to describe an asymmetry of $28.5 \%$ of $\geq 5 \mathrm{~mm}$ in their researched population. This may lead to the conclusion that quantifying shortening using this method may be unreliable for a significant portion of the population. Unlike Cunningham et al. [19], the present study did investigate the effect of dominant side on clavicular length.

To our knowledge, this study is the first to describe the statistically significant association between clavicle length and dominant side and sex $(p<0.001)$.

A significantly shorter length of the right clavicle and dominant side of, respectively, 1.79 and $1.77 \mathrm{~mm}$ was found. The negative association between hand size and dominant side found by Manning et al. [20] seems also to be true for clavicle length and dominance. The number of right-sided dominance found in our study is in concordance with that of the normal population [19].

Some potential limitations have to be discussed. It should be noted that the only way of assessing fractures of the clavicle in the past is using the patient history. This could introduce the chance of recall bias. It can be argued that not everybody who denied having had a fracture of the clavicle would remember the event of clavicle fractures during birth. However, only $2.0-2.7 \%$ of deliveries cause a birth-related clavicle fracture, so the influence of this could be deemed insignificant, since an asymmetry $\geq 5 \mathrm{~mm}$ in $30 \%$ in the studied population was found [27-29]. Another limitation could be that it can be difficult of identify the true extent of the lateral end of the clavicle on CT, particularly on 3D-CT reconstructions. To minimize variability, a training session for the observers and using a standardized measurement methodology was included. A CCC of 0.99 showed this strategy results in a reliable identification of the right point at the lateral end of the clavicle. A third limitation could be the fact that the measurements were performed once by each observer. However, Cunningham et al. [19] reported a strong interobserver reliability with an ICC ranging from 0.70 to 0.86 as well as similar observed length differences (within 1-2 mm) for all observers. Furthermore, a recent study by Goudie et al. [24] used one observer under the assumption $\mathrm{CT}$ measurements of the clavicle are precise.

\section{Conclusion}

This study demonstrates that $30 \%$ of patients have clavicular side-to-side asymmetry of $5 \mathrm{~mm}$ or more. A significant association between clavicle length and dominant side or sex was found $(p<0.001)$. Utilizing a treatment algorithm based upon symmetry, therefore, has a potential for error and can lead over- or under-treatment of the fractured clavicle. To optimize reliability of imaging and measuring shortening of the fractured clavicle, more research is needed. One should consider natural asymmetry, imaging modality and technique, patient positioning, and method for measuring to identify a standardized and reliable method to adequately use the amount of shortening in the treatment algorithm the fractured clavicle.

Funding There is no funding source.

\section{Compliance with ethical standards}

Conflict of interest The authors declare that they have no conflict of interest.

Ethical approval This article does not contain any studies with human participants or animals performed by any of the authors.

Open Access This article is distributed under the terms of the Creative Commons Attribution 4.0 International License (http://creativeco mmons.org/licenses/by/4.0/), which permits unrestricted use, distribution, and reproduction in any medium, provided you give appropriate credit to the original author(s) and the source, provide a link to the Creative Commons license, and indicate if changes were made.

\section{References}

1. Huttunen TT, Launonen AP, Berg HE, Lepola V, FellanderTsai L, Mattila VM (2016) Trends in the incidence of clavicle fractures and surgical repair in Sweden: 2001-2012. J Bone Jt Surg Am 98(21):1837-1842

2. Canadian Orthopaedic Trauma S (2007) Nonoperative treatment compared with plate fixation of displaced midshaft clavicular fractures. A multicenter, randomized clinical trial. J Bone Jt Surg Am 89(1):1-10

3. Lenza M, Faloppa F (2015) Surgical interventions for treating acute fractures or non-union of the middle third of the clavicle. Cochrane Database Syst Rev 5:CD007428

4. Kong L, Zhang Y, Shen Y (2014) Operative versus nonoperative treatment for displaced midshaft clavicular fractures: a metaanalysis of randomized clinical trials. Arch Orthop Trauma Surg 134(11):1493-1500

5. Hill JM, McGuire MH, Crosby LA (1997) Closed treatment of displaced middle-third fractures of the clavicle gives poor results. J Bone Jt Surg Br 79(4):537-539

6. Lazarides S, Zafiropoulos G (2006) Conservative treatment of fractures at the middle third of the clavicle: the relevance of shortening and clinical outcome. J Shoulder Elbow Surg 15(2):191-194

7. McKee MD, Wild LM, Schemitsch EH (2003) Midshaft malunions of the clavicle. J Bone Jt Surg Am 85-A(5):790-797

8. Chan KY, Jupiter JB, Leffert RD, Marti R (1999) Clavicle malunion. J Shoulder Elbow Surg 8(4):287-290 
9. Eskola A, Vainionpaa S, Myllynen P, Patiala H, Rokkanen P (1986) Outcome of clavicular fracture in 89 patients. Arch Orthop Trauma Surg 105(6):337-338

10. Smekal V, Oberladstaetter J, Struve P, Krappinger D (2009) Shaft fractures of the clavicle: current concepts. Arch Orthop Trauma Surg 129(6):807-815

11. Jubel A, Schiffer G, Andermahr J, Ries C, Faymonville C (2016) Shortening deformities of the clavicle after diaphyseal clavicular fractures: influence on patient-oriented assessment of shoulder function. Unfallchirurg 119(6):508-516

12. Kulshrestha V, Roy T, Audige L (2011) Operative versus nonoperative management of displaced midshaft clavicle fractures: a prospective cohort study. J Orthop Trauma 25(1):31-38

13. van der Meijden OA, Gaskill TR, Millett PJ (2012) Treatment of clavicle fractures: current concepts review. J Shoulder Elbow Surg 21(3):423-429

14. Axelrod DSO, Axelrod T, Whyne C, Lubovsky O (2013) Fractures of the clavicle: which X-ray projection provides the greatest accuracy in determining displacement of the fragments? J Orthop Trauma 13:3

15. Backus JD, Merriman DJ, McAndrew CM, Gardner MJ, Ricci WM (2014) Upright versus supine radiographs of clavicle fractures: does positioning matter? J Orthop Trauma 28(11):636-641

16. Jones GL, Bishop JY, Lewis B, Pedroza AD, Group MS (2014) Intraobserver and interobserver agreement in the classification and treatment of midshaft clavicle fractures. Am J Sports Med 42(5):1176-1181

17. Silva SR, Fox J, Speers M et al (2013) Reliability of measurements of clavicle shaft fracture shortening in adolescents. J Pediatr Orthop 33(3):e19-22

18. Smekal V, Deml C, Irenberger A et al (2008) Length determination in midshaft clavicle fractures: validation of measurement. $\mathrm{J}$ Orthop Trauma 22(7):458-462

19. Cunningham BP, McLaren A, Richardson M, McLemore R (2013) Clavicular length: the assumption of symmetry. Orthopedics 36(3):e343-347
20. Manning JT, Fink B (2008) Digit ratio (2D:4D), dominance, reproductive success, asymmetry, and sociosexuality in the BBC Internet Study. Am J Hum Biol 20(4):451-461

21. Taaffe DR, Lewis B, Marcus R (1994) Quantifying the effect of hand preference on upper limb bone mineral and soft tissue composition in young and elderly women by dual-energy X-ray absorptiometry. Clin Physiol 14(4):393-404

22. Carrasco JL, King TS, Chinchilli VM (2009) The concordance correlation coefficient for repeated measures estimated by variance components. J Biopharm Stat 19(1):90-105

23. Carrasco JL, Phillips BR, Puig-Martinez J, King TS, Chinchilli VM (2013) Estimation of the concordance correlation coefficient for repeated measures using SAS and R. Comput Methods Programs Biomed 109(3):293-304

24. Goudie EB, Clement ND, Murray IR et al (2017) The influence of shortening on clinical outcome in healed displaced midshaft clavicular fractures after nonoperative treatment. J Bone Jt Surg Am 99(14):1166-1172

25. McBride GB (2005) A proposal for strength-of-agreement criteria for Lin's Concordance Correlation Coefficient. NIWA Client Report

26. Carrasco JLMJ (2015) cccrm: concordance correlation coefficient for repeated (and non-repeated) measures (Package version 1.2.1.)

27. Brough AL, Bennett J, Morgan B, Black S, Rutty GN (2013) Anthropological measurement of the juvenile clavicle using multidetector computed tomography-affirming reliability. J Forensic Sci 58(4):946-951

28. Levine MG, Holroyde J, Woods JR Jr, Siddiqi TA, Scott M, Miodovnik M (1984) Birth trauma: incidence and predisposing factors. Obstet Gynecol 63(6):792-795

29. Oppenheim WL, Davis A, Growdon WA, Dorey FJ, Davlin LB (1990) Clavicle fractures in the newborn. Clin Orthop Relat Res 250:176-180 